\title{
Role of life events in the onset of obsessive compulsive disorder
}

\author{
Chetali V. Dhuri, Shubhangi R. Parkar
}

\section{Introduction}

Research into the onset of obsessive-compulsive disorder (OCD) suggests the occurrence of potential life events as triggering factors; however, such an association has not been well established.

Aims

To assess the role of life events in the onset of OCD. Method

Fifty patients, ages ranging from 18 to 60 years, belonging to either sex, meeting the DSM-IV TR diagnostic criteria for OCD and attending a tertiary care psychiatric clinic were selected for the study. The Presumptive Stressful Life Events Scale (PSLES) was administered to them to obtain information regarding the presence of life events in a one year period prior to the onset of OCD. Other specific life events not included in the PSLES were also noted.
Results

Sixty four per cent of the sample was male and $78 \%$ of the sample experienced stressful life events in the year prior to the onset of symptoms. Appearing for an exam or interview was most frequent $(10 \%)$, followed by violation of religious or cultural beliefs $(8 \%)$ and the death of a close family member $(6 \%)$. A third of the females studied had life events relating to the reproductive cycle. Half of the sample had onset of OCD during adolescence with $75 \%$ of them subjects reporting preceding stressful life events.

\section{Conclusion}

Life events appear to have a close association with the onset of OCD. These findings suggest that life events may act as triggers predisposing vulnerable individuals to develop the disorder.

SL J Psychiatry 2014; 5 (1):10-13

\section{Introduction}

A life event is a significant occurrence involving a relatively abrupt change that may produce serious and long lasting effects (1). Life events can either be pleasant and contributory in nature, wherein the stress is called 'Eustress' or unpleasant and destructive in nature, where the stress is called 'Dystress' (2). Research has demonstrated that life event related stresses may result in both physical and mental health problems (3). The relationship between stressful life events and psychiatric disorders, such as schizophrenia $(4,5)$ and depression $(6,7)$ has been well documented. Similarly the relationship between anxiety disorders and 'danger' events has also been observed (8). Certain life events are associated with specific mental disorders such as bereavement leading to depression (6).Bereavement and economic difficulties have been reported to precede mania (9). Other stressful events are known to be associated with the course of the illness in anxiety disorders (10).

Only a few studies have investigated the role of such events specifically in obsessive compulsive disorder (OCD). Some of these studies have reported a significant excess of undesirable life events prior to the onset of the illness $(11,12,13)$. On the contrary, other studies did not observe any significant difference in the occurrence of desirable and undesirable life events prior to onset in their samples of OCD patients $(14,15)$. This research attempts to examine the occurrence of various life events prior to the onset of OCD.

\section{Method}

A cross sectional study was conducted over a period of one year in the outpatient department in a tertiary care hospital. The study group comprised of 50 subjects over the age of 18 years and a Diagnostic and Statistical Manual of Mental Disorders, 4th Edition, Text Revision (DSM-IV TR) diagnosis of OCD. Subjects with intellectual disability, organic mental disorders and the spectrum of psychotic disorders (schizophrenia, schizoaffective disorder, bipolar disorder) as the major axis I disorder were excluded. All participants gave written informed consent to a protocol approved by the institution.

A semi structured pro forma was used for recording the socio-demographic variables, the age of onset and the duration of OCD. Stressful life events occurring in a period of one year prior to the onset of OCD was scored using the Presumptive Stressful Life Events Scale, PSLES (16). The scale is constructed and standardised for use in an Indian population. It is an inventory of 51 items, each item having a weighted stress score; for example: death of spouse $=100$; conflict over dowry $=$ 51 ; going on a pleasure trip $=20$.

The data of stressful life events prior to the onset of OCD was documented and analysed using a frequency distribution. The un-paired $t$ test was used for comparison of mean, for age of onset and the duration of OCD between male and female groups. 


\section{Results}

\section{Socio-demographic variables}

The mean age of the sample was 30.62 years with the range between 18-59 years. Among them, $64 \%$ of the subjects were male while $50 \%$ of the sample was married, $44 \%$ subjects were single, $4 \%$ were separated and $2 \%$ were divorced. With regard to the educational status, $56 \%$ of the subjects had a tertiary education, $34 \%$ had a secondary education, $6 \%$ were primary educated and $4 \%$ were illiterate. Their occupational distribution revealed that $18 \%$ were professionals, $14 \%$ were self-employed, $16 \%$ were in skilled employment, $4 \%$ had unskilled jobs, $28 \%$ were homemakers and others including students and unemployed amounted to $20 \%$.

\section{Age of Onset}

The mean age of onset of OCD was 21.88 years for males and 25.89 years for females (Table 1 ). The mean duration of illness for males and females was 6.56 years and 8.72 years respectively. There was no statistically significant difference in the age of onset or duration between the male and female groups.

\section{Distribution of life events}

In this sample, $78 \%$ of subjects experienced significant life events in the year preceding the onset of illness (Table 2). Among them, $10 \%$ of the subjects had reported more than one life event. Appearing for an exam or interview $(10 \%)$, the death of a close family member $(6 \%)$, major personal illness or injury $(6 \%)$, minor violations of the law $(4 \%)$, change of residence $(4 \%)$ were commonly reported life events. The choice of recording 'other' life event (other than those in the PSLES) was given to the subjects and $20 \%$ of the sample reported other specific life events such as violation of a religious/cultural belief $(8 \%)$, (e.g. obsessive symptoms occurred in a subject after he mistakenly stood with his back facing God while praying), exposure to sexual stimuli (4\%) such as watching pornographic material, injection with a needle used for another person $(2 \%)$, childbirth $(2 \%)$ and menopause $(2 \%)$. Many events listed in the PSLES experienced in mental health conditions illness were not reported. Certain life events included in the scale for both sexes such as pregnancy or pregnancy in spouse $(2 \%)$ and the birth of a daughter $(2 \%)$ were reported exclusively by female subjects.

\begin{tabular}{|c|c|c|}
\hline & Mean (SD) & Significance \\
\hline $\begin{array}{l}\text { Age at onset } \\
\text { Male }(n=32) \\
\text { Female }(n=18)\end{array}$ & $\begin{array}{l}21.88(9.35) \\
25.89(7.49)\end{array}$ & $p=0.125$ \\
\hline $\begin{array}{l}\text { Duration of illness } \\
\text { Male }(n=32) \\
\text { Female }(n=18)\end{array}$ & $\begin{array}{l}6.56(5.63) \\
8.72(8.49)\end{array}$ & $p=0.285$ \\
\hline
\end{tabular}

\begin{tabular}{|c|c|c|}
\hline Life event & $\begin{array}{l}\text { Mean stress } \\
\text { score }\end{array}$ & Frequency (\%) \\
\hline No life event reported & & $11(22)$ \\
\hline $\begin{array}{l}\text { Appearing for an } \\
\text { examination or interview }\end{array}$ & 43 & $5(10$ \\
\hline $\begin{array}{l}\text { Death of a close family } \\
\text { member }\end{array}$ & 66 & $3(6)$ \\
\hline $\begin{array}{l}\text { Major personal illness or } \\
\text { injury }\end{array}$ & 56 & $3(6)$ \\
\hline Minor violation of law & 48 & $2(4)$ \\
\hline Change of residence & 39 & $2(4)$ \\
\hline $\begin{array}{l}\text { Marital separation or } \\
\text { divorce }\end{array}$ & 77 & $1(2)$ \\
\hline Marital conflict & 64 & $1(2)$ \\
\hline $\begin{array}{l}\text { Broken engagement or } \\
\text { love affair }\end{array}$ & 57 & $1(2)$ \\
\hline Illness of family member & 52 & $1(2)$ \\
\hline $\begin{array}{l}\text { Self or family member } \\
\text { unemployed }\end{array}$ & 51 & $1(2)$ \\
\hline $\begin{array}{l}\text { Getting married or } \\
\text { engaged }\end{array}$ & 43 & $1(2)$ \\
\hline Trouble with neighbours & 40 & $1(2)$ \\
\hline $\begin{array}{l}\text { Begining or end of } \\
\text { schooling }\end{array}$ & 36 & $1(2)$ \\
\hline Birth of daughter* & 30 & $1(2)$ \\
\hline 'Others' & & $10(20)$ \\
\hline $\begin{array}{l}\text { Death of a close family } \\
\text { member, 'Other' }\end{array}$ & 66 & $1(2)$ \\
\hline $\begin{array}{l}\text { Conflict with in-laws, } \\
\text { Pregnancy* }\end{array}$ & 57,52 & $1(2)$ \\
\hline $\begin{array}{l}\text { Conflict with in laws, Birth } \\
\text { of daughter* }\end{array}$ & 57,30 & $1(2)$ \\
\hline $\begin{array}{l}\text { Pregnancy*, Family } \\
\text { conflict }\end{array}$ & 52,47 & $1(2)$ \\
\hline Family conflict, 'Others' & 47 & $1(2)$ \\
\hline \multicolumn{3}{|c|}{$\begin{array}{l}\text { Only life events reported by the subject group are included in above table. } \\
\text { 'Others'- includes those life events which are not part of the original scale. } \\
\text { *Reported by female subjects only. }\end{array}$} \\
\hline
\end{tabular}

\section{Discussion}

Stress and environmental factors have been identified as playing a major role in the onset of many disorders such as major depressive disorder, bipolar affective disorder and schizophrenia. In this study $78 \%$ of subjects experienced stressful life events in the year prior to the onset of OCD. This finding is in accordance with western data reporting a significantly higher mean life event score in OCD subjects, six months prior to the onset of the illness compared to control subjects (11). Other Indian studies have also reported more undesirable life events in patients with OCD than in controls $(12,13)$.

A few studies have also explored the role of the specific nature of life events in OCD. Khanna (1988) reported uncontrolled life events related to physical health and bereavement (12), while Sarkel et al (2011) reported 
that change of residence and undertaking examinations were more frequent (17). In this study, undertaking an examination was the most frequent $(10 \%)$, followed by violation of religious/cultural beliefs $(8 \%)$, bereavement $(6 \%)$, physical health problems $(6 \%)$ and a change of residence $(4 \%)$.

In this sample, $50 \%$ of subjects had an onset of OCD during adolescence (10-20 years), a period characterised by a high level of sex hormones. Also interestingly, $33.33 \%$ of female subjects had preceding life events related to their reproductive cycle i.e. pregnancy, childbirth and menopause. In two studies addressing the role of pregnancy in OCD, Neziroglu et al(1992) and Williams et al (1997) found pregnancy to be associated with onset of OCD in $39 \%$ and $13 \%$ patients respectively $(18,19)$. Studies have suggested the role of estrogen and progesterone altering serotonergic function, placing some women at a higher risk for psychiatric disorders in postpartum period $(20,21)$. Oxytocin is found to be elevated in the cerebrospinal fluid of some patients with postpartum OCD (22). Concurrent life events such as undertaking an examination, bereavement, conflict with in-laws and other family conflicts were reported by a majority of subjects with the onset of OCD during adolescence $(75 \%)$ in this study.

Though stresses related to life events may result in either physical or mental health problems, it has been observed that the vast majority of individuals faced with serious life events do not develop a psychological impairment. An individual with an inherent vulnerability is more likely to succumb to the development of psychopathology if a certain stress is encountered. The role of vulnerability factors such as a genetic predisposition (23), temperament (24) and dysfunctional orbito-fronto-thalamic circuit (25) is well established in the onset of OCD. Our study results suggest that hormonal imbalances, such as those seen during adolescence, could be an important biological vulnerability factor for OCD.

\section{Conclusion}

The results of the present study suggest that life events have a close association with the onset of OCD. Appearing for an examination or interview was the most frequently reported event. Also, more than $50 \%$ of the sample experienced the onset of OCD either during adolescence or events related to the reproductive cycle and the majority of them experienced concurrent stressful life events. These findings suggest a high biological vulnerability, especially during periods of hormonal imbalance when life events may act as triggers predisposing vulnerable people to develop the disorder. This is a hypothesis that merits further investigation.

\section{Declaration of interest}

None declared

\author{
Chetali V. Dhuri \\ Shubhangi R. Parkar \\ Department of Psychiatry, Seth G. S.Medical \\ College and KEM Hospital, Maharashtra, India \\ Corresponding author \\ Chetali V. Dhuri \\ E mail: chetali.dhuri@gmail.com
}

\section{References}

1. Settersten RA \& Mayer LU. The measurement of age, age - structuring and the life course. Annual Review of Sociology 1997; 23: 233-261.

2. Bemad J. The endaemonists. In: Klausher SZ.Ed. Why Man Takes Chances. New York: Garden City; 1968.

3. Cohen S. After effects of stress on human performance and social behaviour: A review of research and theory. Psychological Bulletin 1980; 88(1): 82-108.

4. Valillant GE. Prospective prediction of schizophrenic remission. Archives of General Psychiatry 1964; 11: 509-518.

5. Lukoff D, Synder KS, Ventura J \& Nuechterlein KH. Life events, familial stress and coping in the developmental course of schizophrenia. Schizophrenia Bulletin 1984; 10: 258-292.

6. Paykel ES, Dienelt MN, Lindenthal JJ. Life events and depression: A controlled study. Archives of General Psychiatry 1969; 21: 753-760.

7. Chatterjee RN, Mukherjee SP \& Nandi DN. (1981) Life events and depression. Indian Journal of Psychiatry 1981; 23: 4.

8. Cooke DJ, Hole DJ. An etiological importance of stressful life events.Br J Psychiatry 1983; 143: 397.

9. Lakhera KG, Salolki RK and Vyas JN. A study of recent life events and their role in the precipitation of mania. Indian Journal of Psychiatry 1995; 37(1): 13-16.

10. Barret JE. The relationship of life events to the onset of neurotic disorders. In: Barret JE, Rose RM, Klerman GL, eds. Stress and Mental disorders. New York, NY: Raven Press; 1979: 87-109.

11. Gothelf D, Aharonovsky O, Horesh N, Carty T, Apter A. Life events and personality factors in children and adolescents with obsessive compulsive disorder and other anxiety disorders. Compr Psychiatry 2004; 45: 192-198.

12. Khanna S, Rajendra PN \& Channabasavanna SM. Life events and onset of obsessive compulsive disorder. International Journal of Social Psychiatry 1988; 34: 305-309.

13. Kulhara P, Prasad Rao G. Life events in obsessive compulsive neurosis. Indian J Psychiatry 1986; 28 : 221-224.

14. Maina G, Albert U, Bogetto F, Vaschetto P, Ravizza L. Recent life events and obsessive-compulsive disorder (OCD): the role of pregnancy/delivery. Psychiatry Res. 1999; 89(1):49-58.

15. McKeon J, Roa B and Mann A. Life Events and Personality Traits In Obsessive Compulsive Neurosis. British Journal of Psychiatry 1984; 144 : 185-189. 
16. Singh G, Kaur D \& Kaur H. Presumptive stressful life events scale (PSLES). A new stressful life event scale for use in India. Indian Journal of Psychiatry 1984; 26 (2): 107-114.

17. Sujit Sarkhel, Samir Kumar Praharaj, and Vinod Kumar Sinha. Role of Life Events in Obsessive Compulsive Disorder. Isr J Psychiatry Relat Sci 2011; 48: 3.

18. Neziroglu F, Anemone R, Yaryura-Tobias J: Onset of obsessive compulsive disorder in pregnancy. Am J Psychiatry 1992; 149: 947-950.

19. Williams K, Koran L. Obsessive-compulsive disorder in pregnancy, the puerperium, and the premenstrual. J Clin Psychiatry 1997; 58: 330-334.

20. Sichel DA, Cohen LS, Dimmock JA, et al. Postpartum obsessive compulsive disorder: a case series. J Clin Psychiatry 1993; 54: 156-159.

21. Wisner KL, Peindl KS, Gigliotti T, et al. Obsessions and compulsions in women with postpartum depression. J Clin Psychiatry 1999; 60: 176-180.

22. Leckman JF, Goodman WK, North WG, et al. Elevated cerebrospinal fluid levels of oxytocin in obsessive-compulsive disorder: comparison with Tourette's syndrome and healthy controls. Arch Gen Psychiatry 1994; 51: 782-792.

23. Rasmussen SA, Tsuang MT. Clinical characteristics and family history in DSM III obsessive compulsive disorder, Am J Psychiatry 1986; 143: 317-22.

24. Kim SJ, Kang JI \& Kim CH. "Temperament and character in subjects with obsessive-compulsive disorder" Comprehensive Psychiatry 2009; 50: 567-572.

25. Deckersbach T, Dougherty DD, Rauch SL: Functional imaging of mood and anxiety disorders. J Neuroimaging 2006; 16: 1-10. 